\title{
Review
}

\section{Roll forming of partially heated cold rolled stainless steel}

\author{
Michael Lindgren*, Ulf Bexell, Lars Wikström
}

Dalarna University, 78188 Borlänge, Sweden

\section{A R T I C L E I N F O}

Article history:

Received 2 July 2007

Received in revised form

18 July 2008

Accepted 29 July 2008

Keywords:

TRIP steel

High-strength steel

Roll forming

Partial heat treatment

\begin{abstract}
A B S T R A C T
Today you will find roll formed details in many different products, for example buildings, household appliances and vehicles. The industry, in order to save weight, tends to use more and more high strength steel. The disadvantage with these materials is that they can be difficult to form due to reduced ductility. A way to increase the ductility in the forming areas is by partially heat the steel.

It is shown that partial heating substantially increases the ductility of high strength steel and make it possible to roll form large bend angles. When roll forming, the material will work hardening almost to the as-received condition in the outer and inner radius of the roll formed profile. Furthermore, the heating power decides the bend angle obtained. Finally, the mechanical properties after heating and roll forming are discussed.
\end{abstract}

(c) 2008 Elsevier B.V. All rights reserved.

\section{Contents}

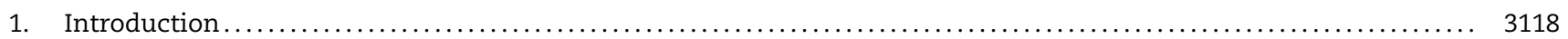

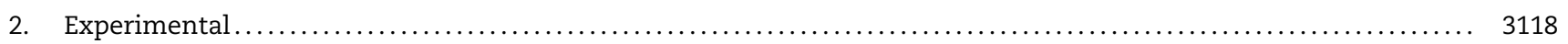

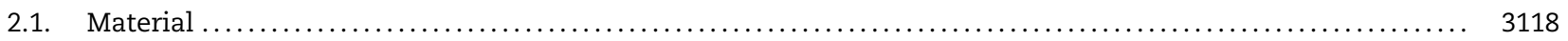

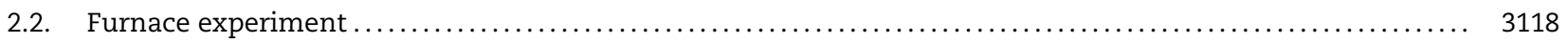

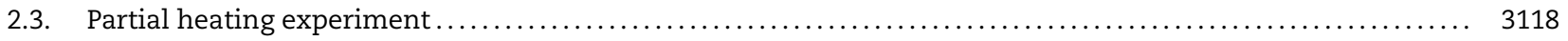

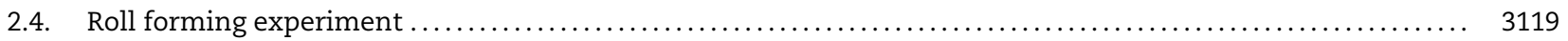

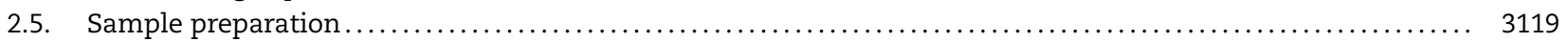

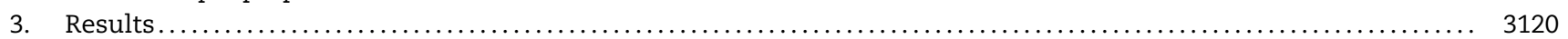

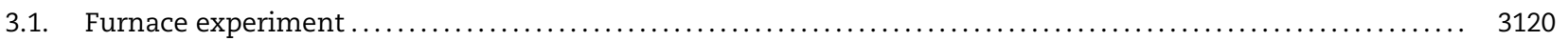

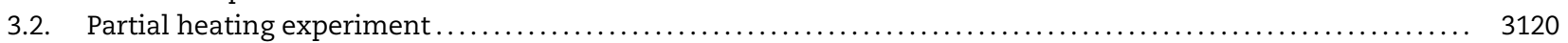

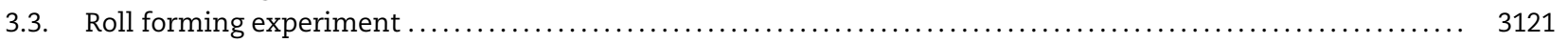

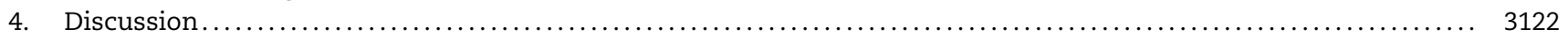

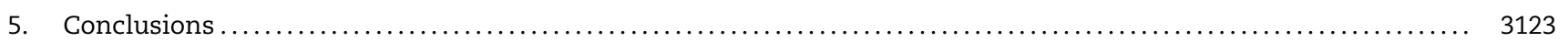

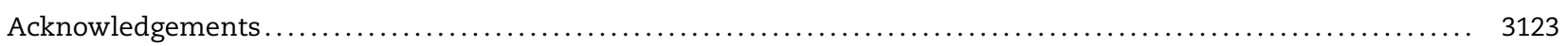

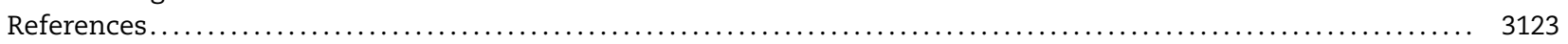

* Corresponding author. Tel.: +46 23 778741; fax: +46 23778601.

E-mail address: mld@du.se (M. Lindgren).

0924-0136/\$ - see front matter @ 2008 Elsevier B.V. All rights reserved.

doi:10.1016/j.jmatprotec.2008.07.041 
1.

\section{Introduction}

Roll forming is a forming process for sheet metal, which has gained in popularity due to high production rates and the possibility to form complex geometries. By including processes, as welding, riveting and punching in the same production line, it is possible to manufacture near net shape products from sheet metal. In order to save weight, the industry tends to use more high strength steels. One problem when forming high strength steels is their low ductility. When a high strength steel product of complex geometry is desired it is possible to use an austenitic stainless steel, e.g. AISI 301, in its annealed condition. This type of steel has an excellent ductility and strain hardening during forming resulting in high strength in the formed areas, also called TRIP (TRansformation Induced Plasticity) steels. However, the unformed parts will remain soft. An alternative method to produce a complex geometry is to start with this type of steel in a cold rolled condition and increase the ductility in the forming areas by partial heating. This approach will give products with high strength properties also in undeformed areas. The latter approach is preferable in roll forming, where it is desired to concentrate plastic deformation to the bending areas. Furthermore, the heated areas will strain hardening and regain some of the lost strength during roll forming.

In a study conducted by Mumtaz et al. (2004) it was concluded that specimens of a 304 type austenitic stainless steel rolled to $55 \%$ reduction in thickness produced $74 \% \alpha^{\prime}$ martensite phase. In this study cold rolled AISI 301 steel, rolled to a reduction of $57.5 \%$ in thickness, has been partially heated and roll formed. Thus, the as-received material in this study should have similar high strain induced $\alpha^{\prime}$-martensite phase content. Upon heating the material will soften due to recovery, recrystallization and phase transformations. The recovery is manly attributed to the annihilation and rearrangement of dislocations. A complete recovery is seldom achieved without recrystallization, a process where grains with high defect density is replaced with new defect free grains. Johannsen et al. (2006) concluded, for annealing temperatures higher than $800^{\circ} \mathrm{C}$, that the microstructure consists of recrystallized grains of austenite and minor carbides, majority of the carbides were found in the grains and not at the grain boundaries. Di Schino et al. (2002) studied the austenite-martensite transformation under cold rolling deformation followed by annealing in a 304 stainless steel. The purpose with the investigation was to study the effect of thermo-mechanical processes on grain refinement. It was concluded that an increased reduction in thickness gives a more homogenous grain size and a more recrystallized microstructure using the same annealing time and temperature.

When the heated areas of the material are roll formed it will transform back to $\alpha^{\prime}$-martensite from austenite, $\gamma$-phase. The phase transformation is a nucleation and shear process where austenite, transforms into $\varepsilon$-martensite and $\alpha^{\prime}$-martensite. It is believed that the $\varepsilon$-martensite acts as an intermediate phase in the transformation sequence $\gamma \rightarrow \varepsilon \rightarrow \alpha^{\prime}$ as discussed in the papers by Mészáros and Prohászka (2005) and Spencer et al. (2004). It should be noted that this transformation sequence is far from fully understood as discussed by Petit et al. (2007),

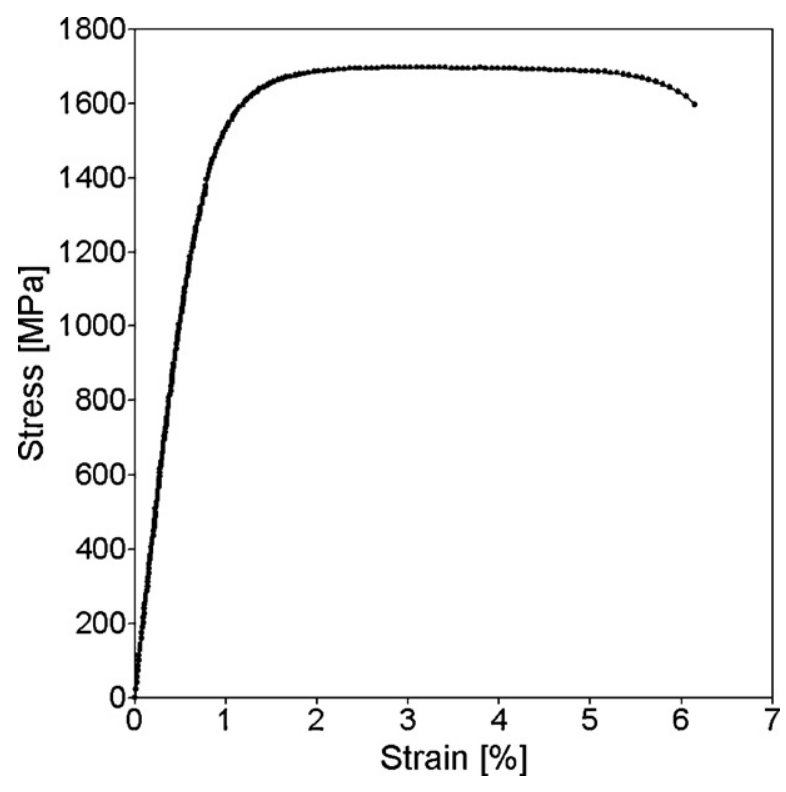

Fig. 1 - The tensile test data for an as-received HyTens ${ }^{\circledR}$ 1600.

particularly the role of $\varepsilon$-martensite on the formation of $\alpha^{\prime}$ martensite.

The aim of the present investigation is to apply partial heating to a cold rolled AISI 301 stainless steel. The influence of resistance heating on the material in the bending area before and after roll forming will be investigated.

\section{Experimental}

\subsection{Material}

The investigated material, HyTens ${ }^{\circledR} 1600$, is a cold rolled stainless steel. The composition satisfies the grade of AISI 301. The total reduction after the last annealing step is $57.5 \%$ resulting in a yield strength $R_{\mathrm{p} 0.2}$ of $1460 \mathrm{MPa}$, an average hardness of $580 \mathrm{HV}_{0.5}$ and a thickness of $0.7 \mathrm{~mm}$. In Fig. 1 a tensile test of the material is presented and in Fig. 2 the microstructure is shown. The microstructure shows a typical cold deformed structure with heavily deformed austenite grains which are transformed to $\alpha^{\prime}$-martensite.

\subsection{Furnace experiment}

Flat samples of $0.7 \mathrm{~mm} \times 15 \mathrm{~mm} \times 84 \mathrm{~mm}$ in size were heat treated in an electrical batch furnace followed by quenching in water. The heat treatment time was $15,30,60,90$, and $120 \mathrm{~s}$, respectively, with temperatures ranging from $500^{\circ} \mathrm{C}$ up to $1200^{\circ} \mathrm{C}$, in steps of $100^{\circ} \mathrm{C}$.

\subsection{Partial heating experiment}

The partial heating was performed in a prototype resistance heating machine, see Fig. 3. The diameters of the heating wheels are $122.5 \mathrm{~mm}$ and the width of the contact zone between the wheel and the material is $5 \mathrm{~mm}$. The power was 


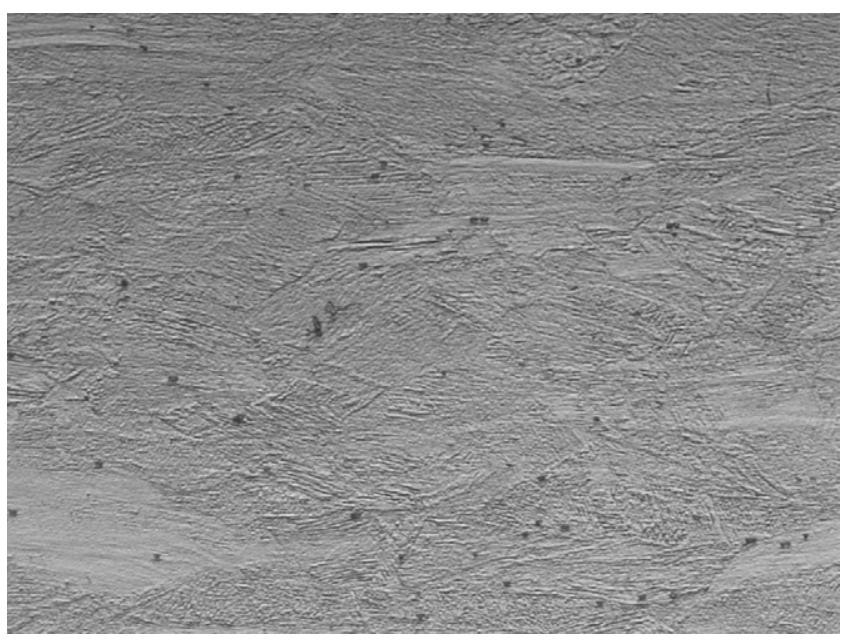

Fig. 2 - Light optical image of the microstructure of an as-received HyTens ${ }^{\circledR} 1600$. The image width is $150 \mu \mathrm{m}$.

adjusted as high as possible without any, for the naked eye, detectable surface defects. This power setting is noted P30. Also, two lower power settings were investigated noted P10 and P20, were P10 is the lowest. The velocity used to heat the material was $1 \mathrm{~m} / \mathrm{min}$ for all power setting.

\subsection{Roll forming experiment}

Halmos (2005) described different types of roll forming machines where the most popular type is the standard inboard machine. This due to the design of the machine, they can be built and used for materials with any thickness and width. In this study such a machine, see Fig. 4, has been used to roll form a V-section. The horizontal distance between the passes is $450 \mathrm{~mm}$. The radius for the upper tools is $70 \mathrm{~mm}$ and for the lower tools $50 \mathrm{~mm}$. The forming velocity used in the experiments was $3.5 \mathrm{~m} / \mathrm{min}$. The forming load was measured with load cells. The measured load was about $500 \mathrm{~N}$. The Vsection is roll formed in six passes where the forming steps are $15^{\circ}, 30^{\circ}, 60^{\circ}, 90^{\circ}, 105^{\circ}$ and $120^{\circ}$, see Fig. 5. Chiang (1984)

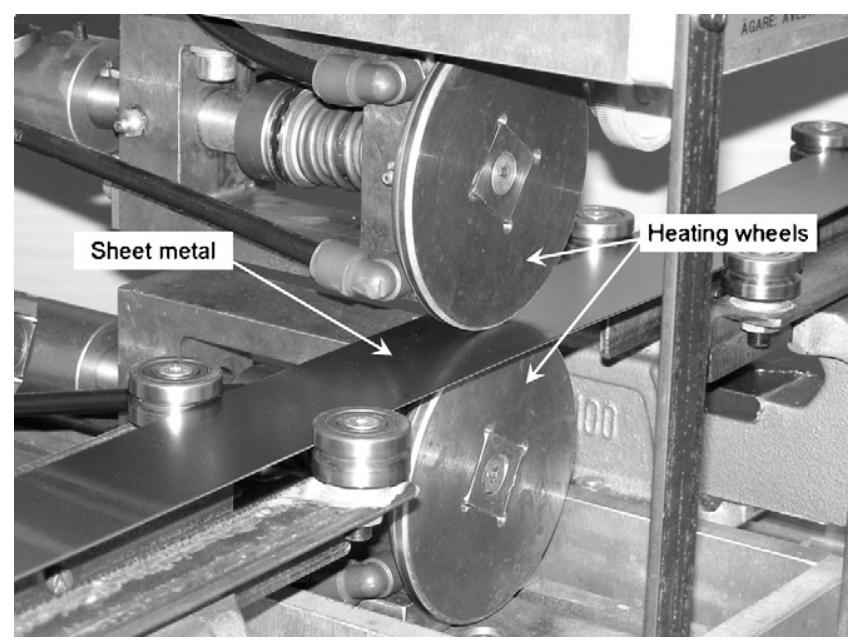

Fig. 3 - Prototype resistance heating machine used for partial heating experiments.

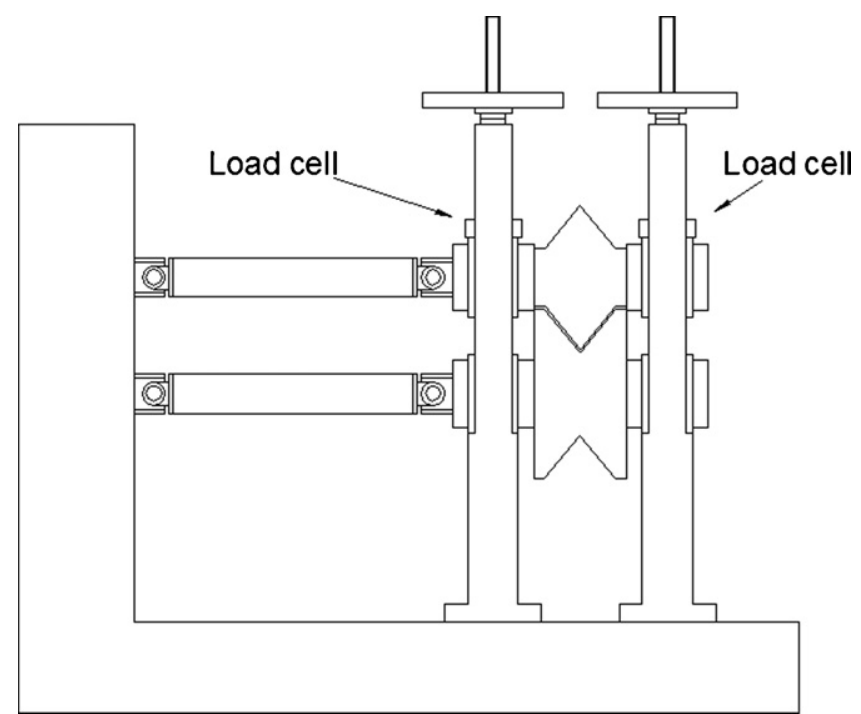

Fig. 4 - Schematics of a standard roll forming machine equipped with load cells.

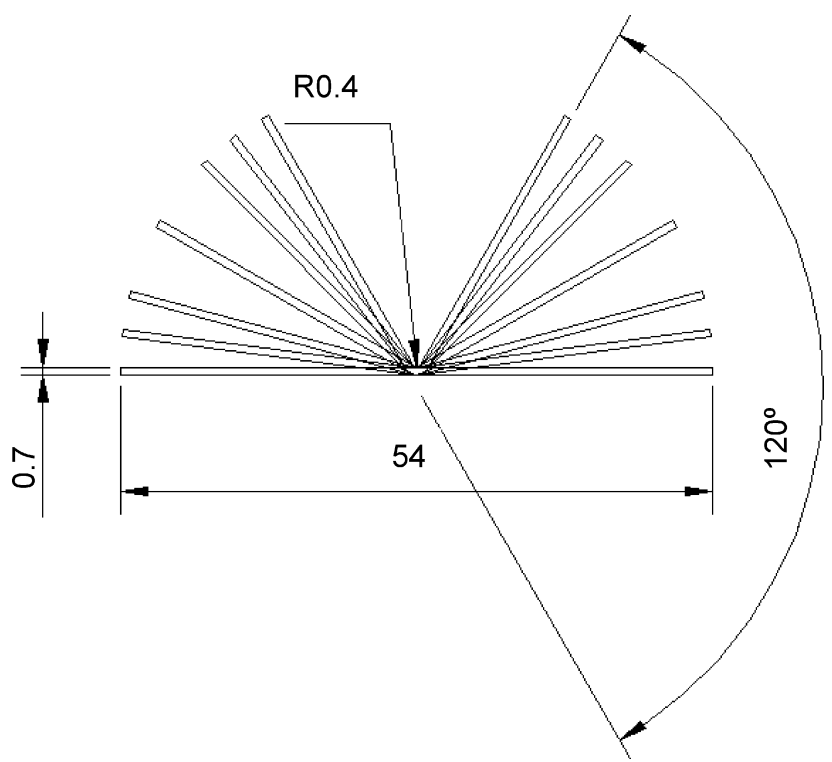

Fig. 5 - The "flower pattern" for the roll formed V-section. The forming steps are $15^{\circ}, 30^{\circ}, 60^{\circ}, 90^{\circ}, 105^{\circ}$ and $120^{\circ}$.

discussed three different ways to bend a corner, "constant arc length" method, "constant radius" method and a mixture of both methods. In this study the "constant radius" method is used to bend the $\mathrm{V}$-section, which means that the inner radius is the same for all passes, in this case $0.4 \mathrm{~mm}$, see Fig. 6 . The width of the unformed material is $54 \mathrm{~mm}$ and the thickness is $0.7 \mathrm{~mm}$.

\subsection{Sample preparation}

Cross-sections, perpendicular to the rolling directions, of all samples were hot mounted using a thermosetting resin followed by mechanical grinding and polishing with $1 \mu \mathrm{m}$ diamond suspension in the last step. Chemical etching was used to reveal the microstructure of the samples. The etching solu- 
tion consisted of $60 \mathrm{ml}$ deionised water, $62 \mathrm{ml}$ concentrated $\mathrm{HCl}, 3 \mathrm{ml}$ concentrated $\mathrm{HNO}_{3}$ and $5 \mathrm{ml}$ concentrated $\mathrm{H}_{2} \mathrm{SO}_{4}$. The etching time was approximately $60 \mathrm{~s}$ at room temperature. To reveal the heated zone in the partially heated samples etching was performed in an etching solution consisting of $25 \mathrm{ml}$ concentrated $\mathrm{HCl}$ and $5 \mathrm{ml} 10 \mathrm{wt} \%$ chrome acid solution in deionised water. In this case, the etching time was 5-10 s. The effect on the material due to the heat treatments and the roll forming was evaluated with Vickers microhardness tests with an applied load of $500 \mathrm{~g}$. All microhardness testing was performed before etching of the samples. The etched cross-sections were examined with light optical microscopy (LOM).

\section{Results}

\subsection{Furnace experiment}

The hardness for different heat treatment temperatures and times are presented in Fig. 7. The results show that at temperatures of $500^{\circ} \mathrm{C}$ and $600^{\circ} \mathrm{C}$ the hardness is almost independent of heat treatment time, i.e. the hardness is the same as for the as-received material. For temperatures in the interval $700-1200^{\circ} \mathrm{C}$ the resulting hardness depends both on time and temperature.

In Fig. 8 the tensile test for a sample heat treated at $1100^{\circ} \mathrm{C}$ for $60 \mathrm{~s}$ is presented. Tensile tests for all heat treatments over $1000^{\circ} \mathrm{C}$ and at different times have similar appearance. Thus, the formability of the material has substantially increased compared with as-received material, cf. Fig. 1. The microstructure of samples heat treated at $1200^{\circ} \mathrm{C}$ for $15 \mathrm{~s}$ and $120 \mathrm{~s}$, respectively, is shown in Fig. 9. As compared to the as-received material, cf. Fig. 2, it can be seen that the material has started to recrystallize already after $15 \mathrm{~s}$ and small austenitic grains has started to grow. Longer heat treatment times give a substantial grain growth as illustrated in Fig. $9 \mathrm{~b}$.

\subsection{Partial heating experiment}

Hardness profiles in the centre and in a near surface region of cross-sections through the partial heated zone for the P10, P20

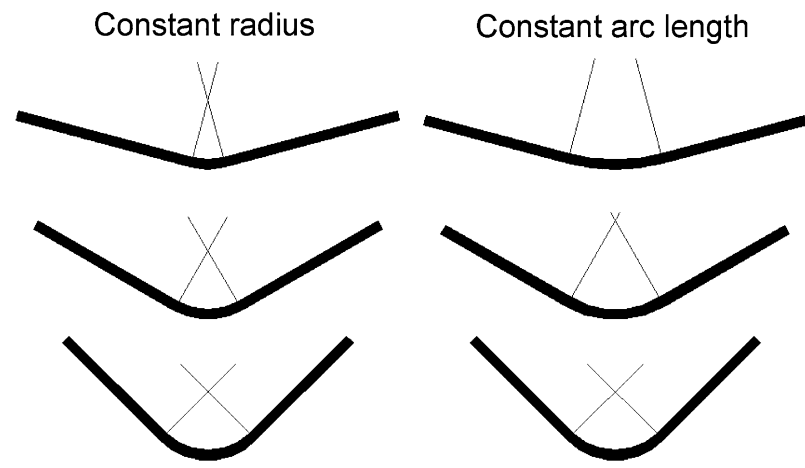

Fig. 6 - Different methods to form a V-section. In the "constant radius" method the tool radius is the same in all forming passes while in the "constant arc length" method the arc length is the same. In the experiments tools with "constant radius" have been used.

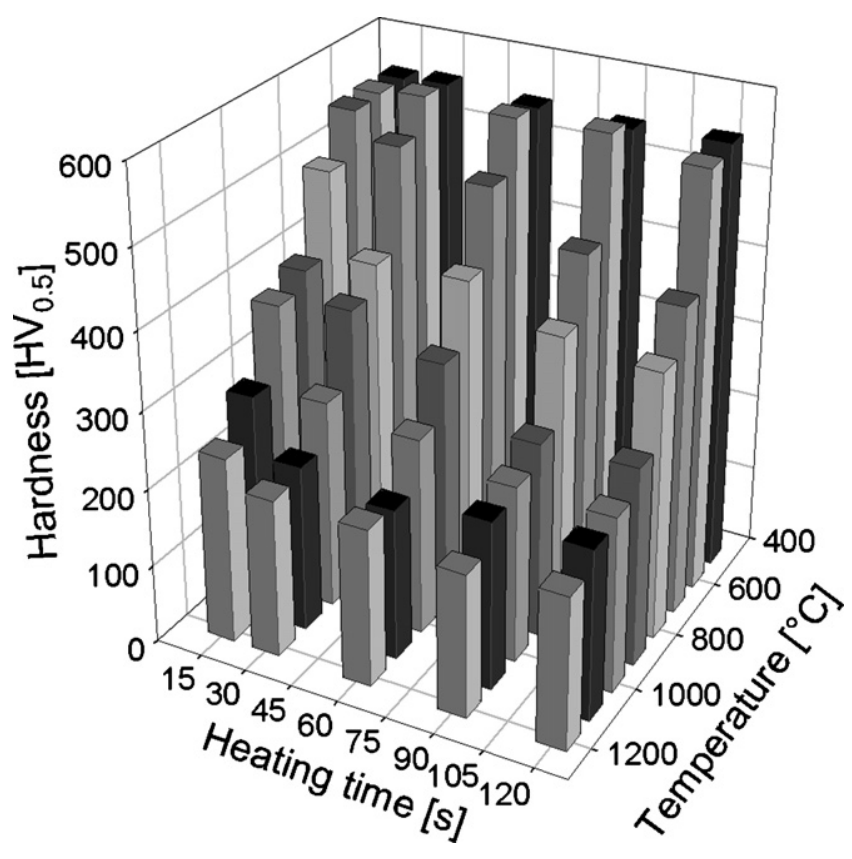

Fig. 7 - Hardness of the material, HyTens ${ }^{\circledR} 1600$, after different heat treatment temperatures and times.

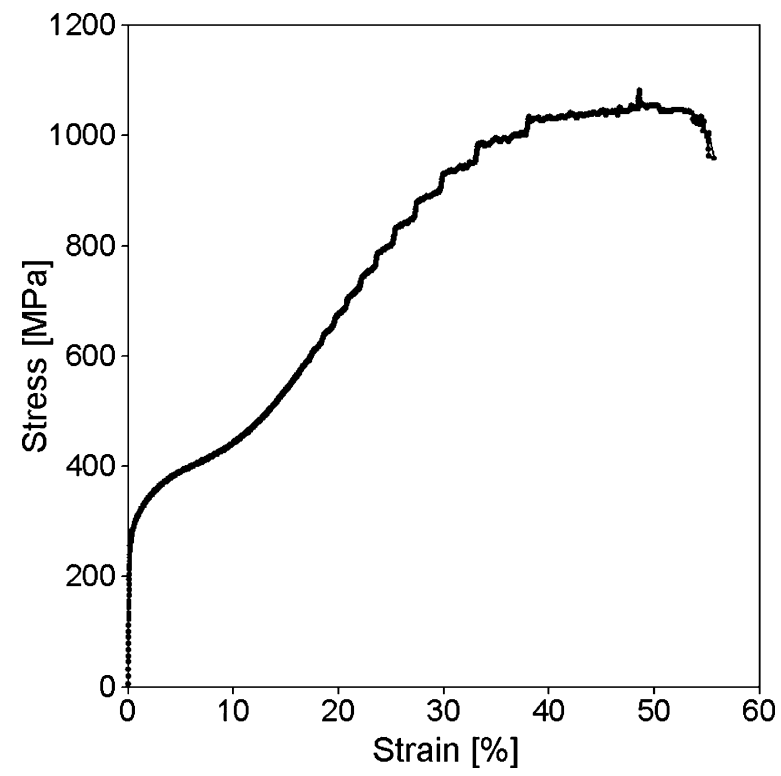

Fig. 8 - Tensile test of the material, HyTens ${ }^{\circledR} 1600$, after a heat treatment at $1100^{\circ} \mathrm{C}$ for $60 \mathrm{~s}$.

and P30 settings, respectively, is presented in Fig. 10. For the P10 setting, see Fig. 10a, the hardness profile indicates that the material is heat affected in a $\sim 2.2 \mathrm{~mm}$ wide zone. The heated zone consists of a transition region were the hardness decreases. The transition region is about $0.6 \mathrm{~mm}$ wide on both sides of a middle region, approximately $1 \mathrm{~mm}$ wide, where the hardness values are at the same level. In the middle region the hardness in the centre of the material is softer, $270-300 \mathrm{HV}_{0.5}$, than the material near the surface, $380-420 \mathrm{HV}_{0.5}$. For the P20 and $\mathrm{P} 30$ samples the transition region has the same width as for the P10 sample. The difference between the samples, i.e. 

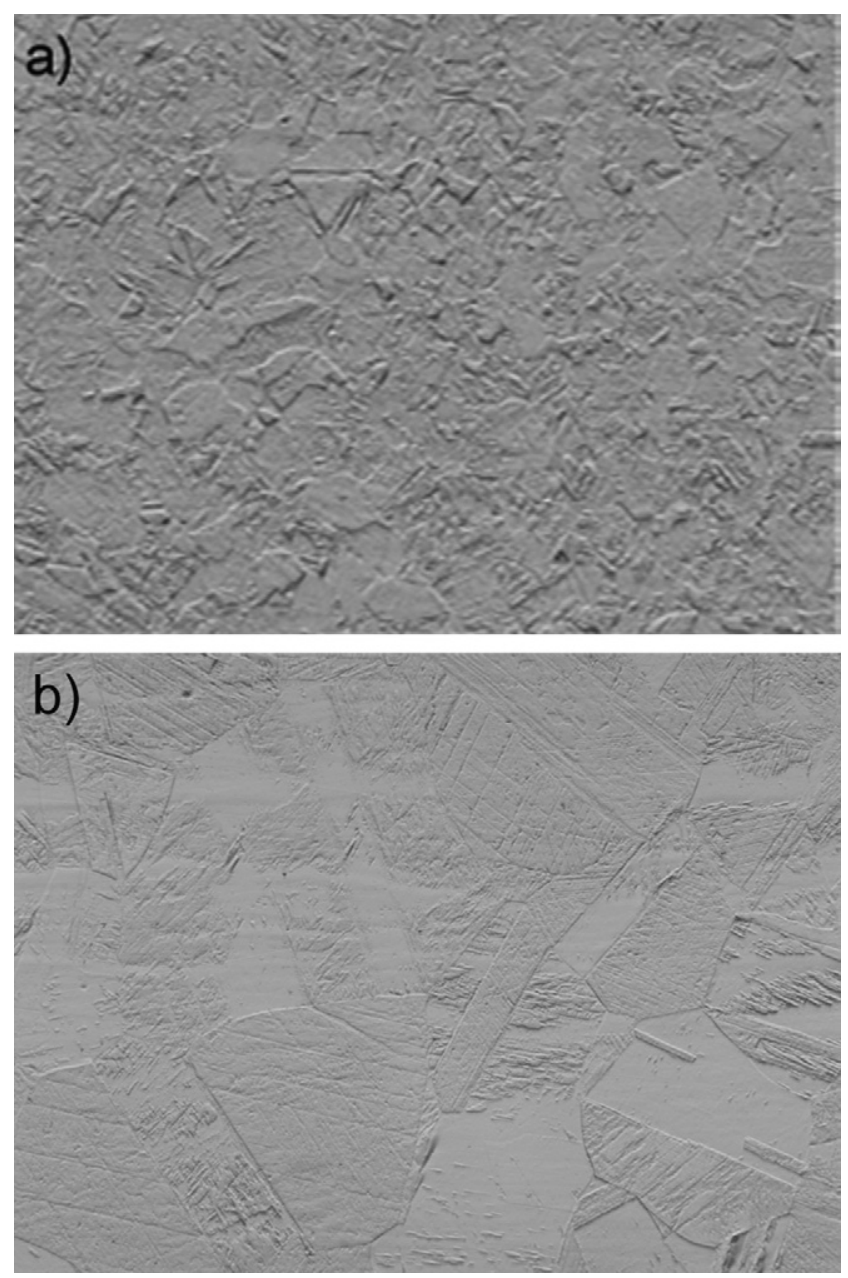

Fig. 9 - LOM images of the microstructure of material heat treated at a temperature of $1200^{\circ} \mathrm{C}$ and a time of $15 \mathrm{~s}$ (a) and $120 \mathrm{~s}$ (b). The image widths are $150 \mu \mathrm{m}$ (a) and $375 \mu \mathrm{m}$ (b), respectively.

different power input, is that the higher power input the wider is the middle region and the hardness in the centre and near the surface approaches the same hardness values. For the P20 sample, see Fig. $10 \mathrm{~b}$, the hardness is $250-270 \mathrm{HV}_{0.5}$ in the centre and $300-320 \mathrm{HV}_{0.5}$ at the near surface. For the P30 sample the hardness is $\sim 260 \mathrm{HV}_{0.5}$ in both the centre and at near surface and the middle region is around $2.2 \mathrm{~mm}$ wide, see Fig 10c.

Fig. 11 shows LOM images of etched cross-sections of the partially heated material for the P10, P20 and P30 settings, respectively. It can be seen that the heating zone starts in the centre of the material and grow towards the surface when the power increases, which also is apparent from the hardness profiles in Fig. 10.

Figs. 12 and 13 show LOM images of the microstructure in the transition and in the middle regions, respectively, for the P30 sample. It can be seen that the material has started to recrystallize in the transition region although the austenite grains are barely visible. In the middle region the material is fully recrystallized and the characteristic structure of austenite grains is seen.

\subsection{Roll forming experiment}

The as-received and the partially heated materials have been roll formed to $120^{\circ}$, in steps of $15^{\circ}, 30^{\circ}, 60^{\circ}, 90^{\circ}, 105^{\circ}$ and $120^{\circ}$. The as-received material could be roll formed to $30^{\circ}$ but ruptured in the bending zone at $60^{\circ}$. The partially heated materials could be roll formed to $120^{\circ}$ without rupture, see Fig. 14. Micro fractures were visible in the bending zone for the P10 sample after forming to a bend angle of $105^{\circ}$.

The hardness in the bending zone after forming to $90^{\circ}, 105^{\circ}$ and $120^{\circ}$ for the P30 sample is presented in Fig. 15. The hardness in the bending zone has increased in the outer and inner radius to $550-600 \mathrm{HV}_{0.5}$. In the neutral layer has the hardness increased $50-100 \mathrm{HV}_{0.5}$ as compared to the not roll formed partially heated P30 sample, cf. Fig. 10c. The thickness reduc-
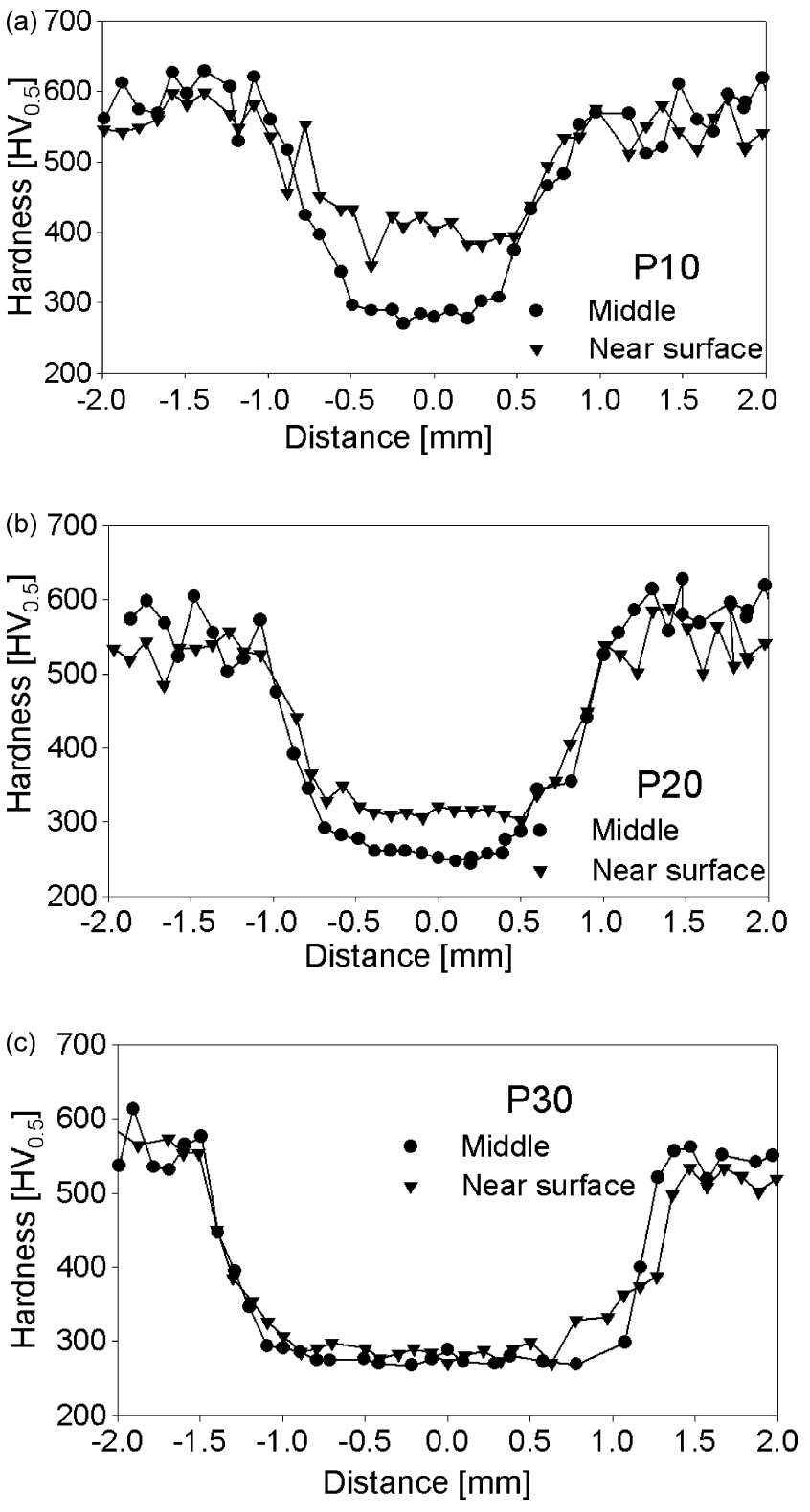

Fig. 10 - Hardness profiles from the power settings (a) P10, (b) P20 and (c) P30 in the centre and at the near surface region of cross-sections of partially heated material. 


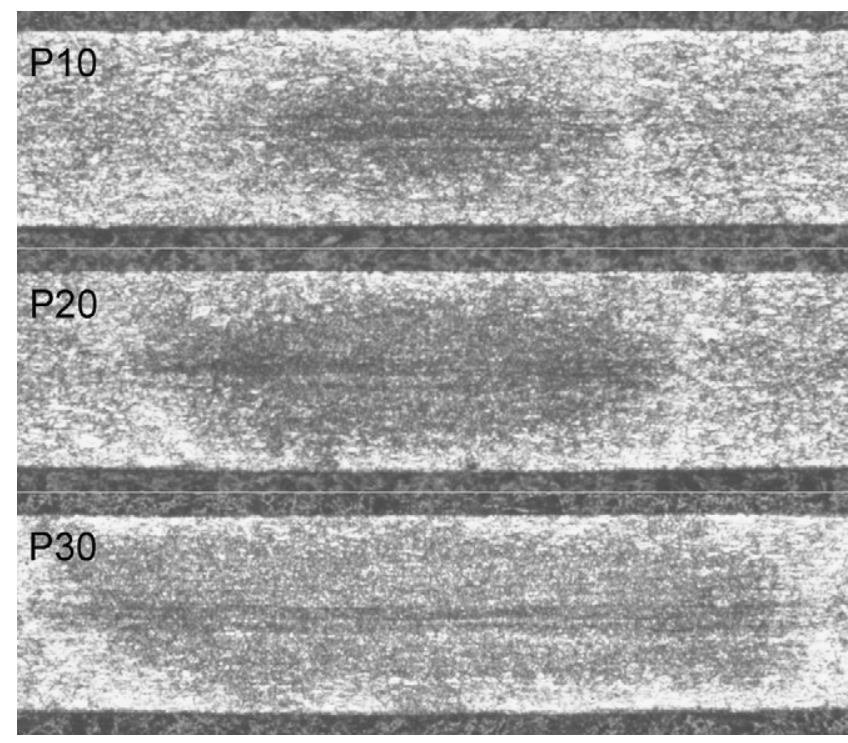

Fig. 11 - Cross-sections of partially heated samples P10, P20 and P30. The image width is $3 \mathrm{~mm}$.

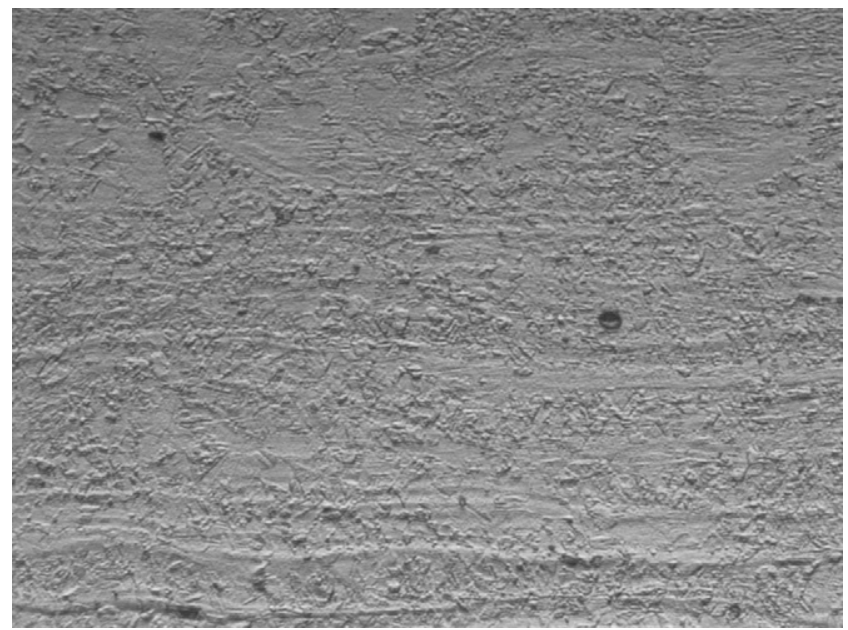

Fig. 12 - The microstructure in the transition region. The image width is $150 \mu \mathrm{m}$.

tion caused by roll forming is about $10 \%$ in the bending zone for all samples as compared to the original thickness. This, in combination with an increasing hardness in the neutral layer, indicates that combined bending and tension has occurred.

Fig. 16 shows the hardness response due to roll forming to a bend angle of $120^{\circ}$ for the P10, P20 and P30 samples, respectively. It can be seen that due to a lower power input the hardness profile is displaced to higher values for the P10 and P20 samples as compared to the P30 sample. The behaviour is similar for the other bending angles.

\section{Discussion}

The velocity, $1 \mathrm{~m} / \mathrm{min}$, used to partially heat the material implies that the time the material is in contact with the heating wheels is very short, for example during $1 \mathrm{~s}$ the material has travelled $16 \mathrm{~mm}$, thus it can be suspected that the moment

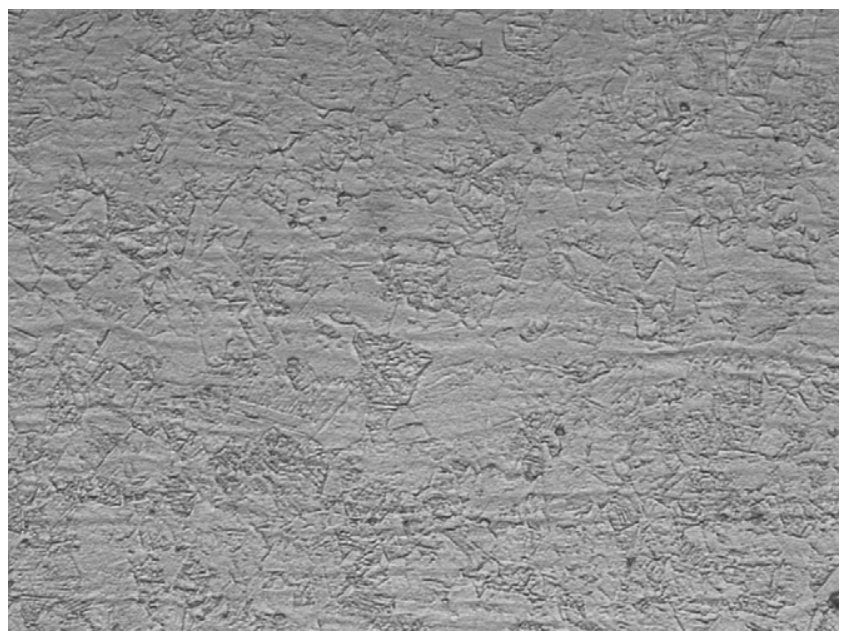

Fig. 13 - The microstructure in the middle region. The image width is $150 \mu \mathrm{m}$.

of heating and cooling is very rapid. The furnace experiments give knowledge about hardness and microstructure changes in the material due to different times and temperatures. When comparing the partially heated material (see Fig. 10) with furnace experiments (see Fig. 7) it was found that the hardness and the microstructure (see Fig. 9a) for a furnace experiment at $1200^{\circ} \mathrm{C}$ for $15 \mathrm{~s}$ (see Fig. 13) agree most with the middle region in all partially heated samples. This implies that the temperature in the middle region must at least reach a temperature of $1200^{\circ} \mathrm{C}$. Furthermore, there is no indication of melting, i.e. a temperature over $1400^{\circ} \mathrm{C}$, thus it can be estimated that the temperature in the middle region is between 1200 and $1400^{\circ} \mathrm{C}$. It should be noted that the furnace and the partially heated experiments are not on the same time scale, but the results clearly show that a relevant comparison is possible. Although the partially heated material reaches a temperature were one

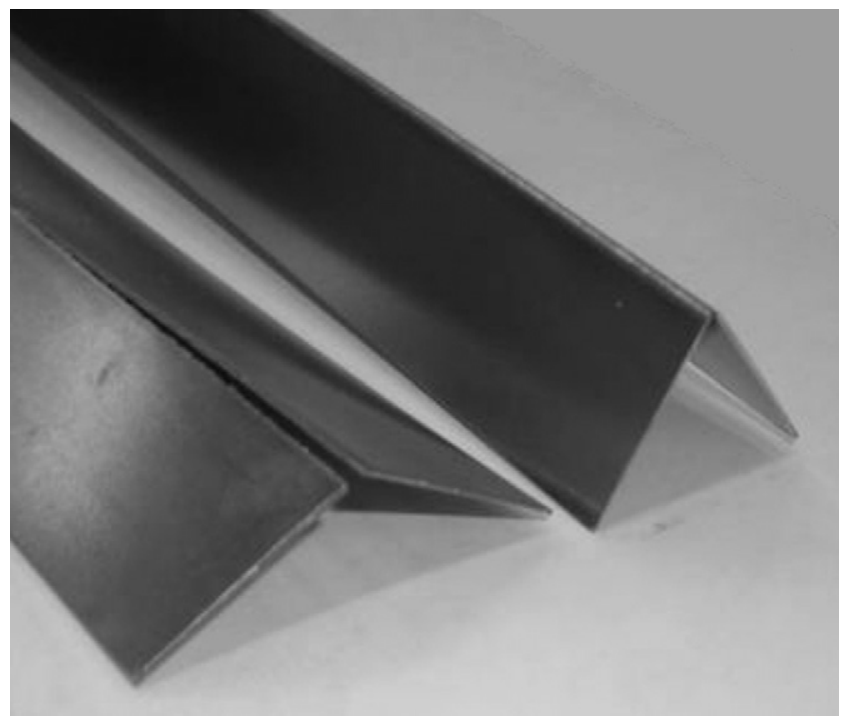

Fig. 14 - The as-received material ruptured in the $60^{\circ}$ forming step. The partially heated material can be roll formed to $120^{\circ}$ without rupture. 


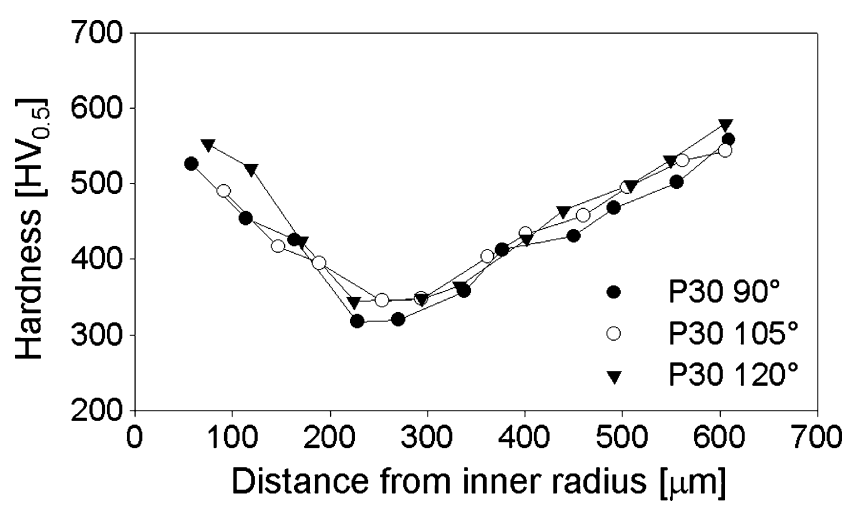

Fig. 15 - The hardness change of the partially heated cross-section due to bending to angles of $90^{\circ}, 105^{\circ}$ and $120^{\circ}$ for sample P30.

can suspect sensitization to occur it is not probable in this case due to the very short heating time, i.e. fractions of a second, which Trillo et al. (1995) also conclude in their study of the combined effect of deformation, grain size and carbon content on carbide precipitation and corrosion sensitization.

The recrystallisation starts in the centre of the material and almost reaches the surface for the P30 sample, cf. Fig. 11, which is also seen in the hardness profiles in Fig. 10. For power inputs lower than P30 it can be seen that the hardness increases towards the surface, i.e. the formability decreases. In a bending operation, as in roll forming, the bending deformation will be largest in the outer (tensile strain) and inner radius (compress strain). This implies that as high power input as necessary should be used without reaching the melting temperature or that surface damage occur to reach full formability. However, depending on the wanted bending angle a lower input can be used. For example, using the power settings for the P10 sample is enough for a bending angle of $90^{\circ}$ but not for $105^{\circ}$ where some micro fracture appeared.

Fig. 15 shows that the hardness is almost independent of bending angle when considering the three last forming steps, i.e. $90^{\circ}, 105^{\circ}$ and $120^{\circ}$. The hardness in the neutral layer has increased about $50-100 \mathrm{HV}_{0.5}$ as compared to the not roll formed partially heated samples. These observations can be derived to the used bending method, i.e. the "constant

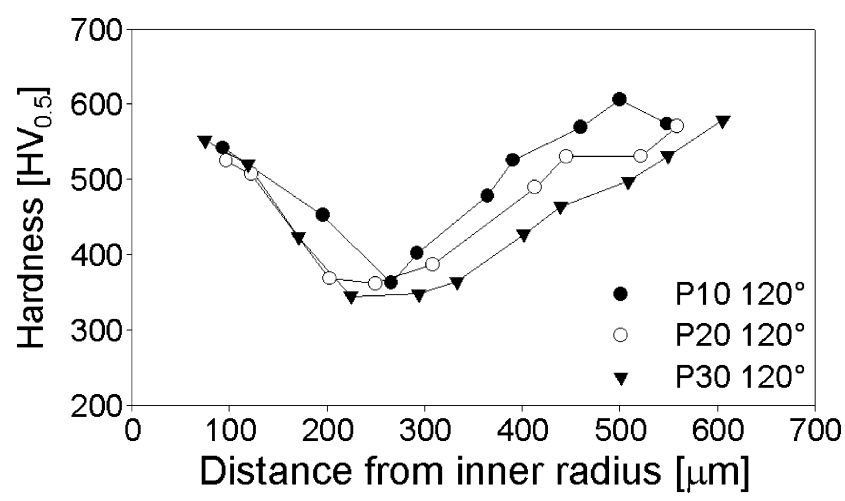

Fig. 16 - The hardness change of the partially heated cross-section due to a bending of $120^{\circ}$ for sample P10, P20 and $\mathrm{P} 30$, respectively. radius" method where it is a constant distance from the bending point to the arc centre in all forming steps. This method will bend a part of the arc length in every forming step to its final shape. This means that the middle part of the arc length is finished already in the $15^{\circ}$ forming step. The method will also give a superimposed tension on the bending. Therefore, the hardness is almost the same for all bending angles since the forming has occurred already in the first forming step. As a consequence of the combined bending and tension this bending method will cause thinning of the sheet metal in the bending zone. In this case, the thickness reduction was about $10 \%$. The increased hardness in the neutral layer verifies the superimposed tension. If the "constant arc length" method (see Fig. 6), which not superimpose tension in the material to the same extent, had been chosen it probably would have been possible to roll form the material with a lower power input to a larger bending angle.

In this study, the only parameter that is varied is the power input. Other parameters such as thickness and yield strength of the material, and the velocity of the heating etc. can be varied. It can be expected that these parameters also will have an influence on the resulting forming properties. However, this study has shown that by partially heating a cold rolled TRIP steel the formability properties has increased substantially thus making it suitable for roll forming.

\section{Conclusions}

In the present study, partial heating of cold rolled TRIP steel has been investigated. The main conclusions are:

- Partial heating substantially increases the formability.

- Too much power input causes surface defects.

- Depending on required bend angle, the power input should be adjusted.

- The partially heated material shows three different regions, unaffected-, transition- and a recrystallized region. The recrystallization starts in the centre and grows with higher power input.

- The material will work hardening almost to the as-received condition in the outer and inner radius of the bending zone during roll forming. The neutral layer will work hardening moderately.

\section{Acknowledgements}

The authors wish to thank ORTIC AB, The Knowledge Foundation (KK-stiftelsen), Jernkontoret, Triple Steelix and Outokumpu Stainless AB for their technical and financial support.

\section{REFERENCES}

Chiang, K.F., 1984. Cold roll forming. M.Sc. Thesis. Mechanical Engineering Department, University of Auckland.

Di Schino, A., Salvatori, I., Kenny, J.M., 2002. Effects of martensite formation and austenite reversion on grain refining of AISI 304 stainless steel. J. Mater. Sci. 37, 4561-4565. 
Halmos, G.T., 2005. Roll Forming Handbook, first ed. CRC Talylor \& Francis, New York.

Johannsen, D.L., Kyrolainen, A., Ferreira, P.J., 2006. Influence of annealing treatment on the formation of nano/submicron grain size AISI 301 Austenitic stainless steels. Metall. Mater. Trans. A 37, 2325-2338.

Mészáros, I., Prohászka, J., 2005. Magnetic investigation of the effect of $\alpha$ '-martensite on the properties of austenitic stainless steel. J. Mater. Process. Technol. 161, 162-168.

Mumtaz, K., Takahashi, S., Echigoya, J., Kamada, Y., Zhang, L.F., Kikuchi, H., Ara, K., Sato, M., 2004. Magnetic measurements of the reverse martensite to austenite transformation in a rolled austenitic stainless steel. J. Mater. Sci. 39, 1997-2010.
Petit, B., Gey, N., Cherkaoui, M., Bolle, B., Humbert, M., 2007. Deformation behavior and microstructure/texture evolution of an annealed 304 AISI stainless steel sheet. Experimental and micromechanical modelling. Int. J. Plast. 23, 323-341.

Spencer, K., Embury, J.D., Conlon, K.T., Véron, M.T., Bréchet, Y., 2004. Strengthening via the formation of strain-induced martensite in stainless steels. Mater. Sci. Eng. A. 387-389, 873-881.

Trillo, E.A., Beltran, R., Maldonado, J.G., Romero, R.J., Murr, L.E., Fisher, W.W., Advani, A.H., 1995. Combined effects of deformation (strain and strain state), grain size, and carbon content on carbide precipitation and corrosion sensitization in 304 stainless steel. Mater. Charct. 35, 99-112. 